\title{
From Panopticon to POV-opticon: Drive to Visibility and Games of Truth.
}

\author{
Mitra Azar \\ Aarhus University \\ Helsingforsgade 14, 8200 Aarhus N, \\ Denmark \\ azar@cc.au.dk
}

\begin{abstract}
The paper proposes a theoretical framework to understand the emergency of the post-truth era in the specific realm of Internet visual culture, and analyses the aesthetic and technological conditions that allow a new form of post-truth to emerge. The paper argues that Internet post-truth could be addressed as the jeu de la verité (game of truth) emerging from the transformation of the Panopticon - the form of visual governamentality of modernity - into the POV-opticon. The POVopticon is a regime of visibility outlined by the explosion of POV (Point of view) technologies of vision - mobile phones, VR and AR technologies - which are transforming POV from a cinematic aesthetic and technical format into one of the most controversial political-aesthetic battlefields of our time. The capability of cinematic POV to produce the seamless overlapping between body and technology is re-invented in relation to new technological devices that re-defines human and machinic agency within new regimes of visibility and new games of truth. The paper tries to understand the POV-opticon by looking at the development of a new type of selfie aesthetic and of a new imagery coming out of the ongoing machinization of the face operated by facial recognition technologies - what l've tried to define elsewhere as the Algorithmic Facial Image (AFI). Especially by defining POV-opticon and AFI, the paper expands the notion of regime of visibility proposed by Dutch art critic Camel van Winkel, and relates it to the notion of games of truth elaborated by Michel Foucault. If, according to Winkel, the regime of visibility is more about the drive to make visible rather than the visible itself, the drive presents a peculiar relation with truthfulness which seems to fit well with the games of truth generated by the POV-opticon. Games of truth is Foucault's attempt to rethinking the concept of regime of truth defining the Panopticon, in relation to distributed forms of governamentality and emerging forms of subjectivity. The paper argues that POV-opticon provides the technological strata for explaining post-truth as the hermeneutical reality emerging from the proliferation of POV games of truth. POV games of truth are assembled into new POV micro-regime of truth algorithmically generated by the extraction of data from the subject and by the creation of a POV data double that works as the algorithmic answer to the drive to visibility and offers a solution to the ambiguities of the games of truth.
\end{abstract}

Panopticon, POV-opticon, games of truth, regime of truth, Algorithmic Facial Image (AFI)

"Faire l'histoire de la vérité, faire l'histoire de jeux de vérité, faire l'histoire de pratiques, des économies, et des politiques de veridiction, faire cette histoire [suppose qu'on ne puisse aucunement] se contenter de dire: Si on a dit telle vérité, c'est que cette vérité étiat réelle. II faut dire au contraire: Le reel étant ce qu'il est, quelles ont été les conditions improbables, les conditions singulières qui ont fait que, par rapport à ce reel, un jeu de la vérité a pu apparaître, avec certes ses raisons, ses nécessités, mais ses raisons et ses nécesittés qui ne sont pas simplement le fait que les choses en question existaient ${ }^{1}$ (Foucault, 198081 [2014], pp. 223-224)?

\footnotetext{
1 "To make the history of truth, to make the history of truth games, to make the history of practices, economies, and policies of veridiction, to make this
}

\section{POV-opticon and games of truth}

The paper proposes a theoretical framework to understand the emergency of the post-truth (ADD $\mathrm{REF}$ ) era in the specific realm of Internet visual culture, and analyses the aesthetic and technological conditions that allow a new form of post-truth to emerge.

history [...] and to be content with saying: if one has said such a truth, it is because this truth is real. On the contrary, it must be said: Since the real is what it is, what were the improbable conditions, the singular conditions which made it possible for a game of truth to appear in relation to this real, certainly with its reasons, its necessities, but its reasons and necessities that are not simply the fact that the things in question existed?". 
The paper argues that Internet post-truth could be addressed as the jeu de la verité (game of truth, Foucault, 1980-81 [2014], pp. 223-224) emerging from the transformation of the Panopticon - the form of visual governamentality of modernity (Foucault, 1975) - into the POV-opticon.

The POV-opticon is a regime of visibility outlined by the explosion of POV (Point of view) technologies of vision - mobile phones, VR and AR technologies, Google Gaze circuit e.g. the ensemble of Google technologies of vision such as Google Maps, Google Car, Google 360 - which are transforming POV from a cinematic aesthetic and technical format into one of the most controversial surveillance and political-aesthetic battlefields of our time. The capability of cinematic POV to produce the seamless overlapping between actor's body, camera, and spectator's body ${ }^{2}$ (Montgomery, 1947; Mirick \& Sanchez, 1999) is re-invented in relation to new technological devices that rearticulate the relation between body and technology in a way that re-defines human and machinic agency within new regimes of visibility and new games of truth.

The paper tries to understand the POV-opticon by looking at the development of a new type of selfie aesthetic and of a new imagery coming out of the ongoing machinization of the face operated by facial recognition technologies - what I've tried to define elsewhere as the Algorithmic Facial Image (AFI) (Azar, 2018).

Especially by defining POV-opticon and AFI, the paper expands the notion of regime of visibility proposed by Dutch art critic Camel van Winkel, and relates it to the notion of games of truth elaborated by Michel Foucault. If, according to Winkel, the regime of visibility is more about the drive to make visible rather than the visible itself (Winkel, 2016), the drive presents a peculiar relation with truthfulness which seems to fit well with the games of truth generated by the POV-opticon. Games of truth is Foucault's attempt to rethinking the concept of regime of truth (Foucault, 1975, p. 30) defining the Panopticon in relation to distributed forms of governamentality (Lorenzini, 2015; 2017) and, more importantly, emerging forms of subjectivity. The paper argues that POV-opticon provides the technological strata for explaining post-truth as the hermeneutical reality emerging from the proliferation of POV games of truth. POV games of truth are assembled into new POV micro-regime of truth algorithmically generated by the extraction of data from the subject and by the creation of a POV data

2 This is what happens in Lady in the Lake by Montgomery (1947), as much as in contemporary experiments of POV movies since at least The Blair Witch project by Mirick \& Sanchez. double $^{3}$ (Azar, 2018) that works as the algorithmic answer to the drive to visibility and offers a solution to the ambiguities of the games of truth.

\section{From Panopticon to POV-opticon}

If in the recent past the Panopticon has been associated with the practice of CCTV surveillance camera (Yar, 2003, pp. 254-271), the contemporary surveillance-assemblage seems to be better formally described by the deployment of POV technologies of vision oriented towards dataveillance (Clarke, 1988, pp. 498-512). One of the reasons for the transformation of the Panopticon into the POV-opticon is the passage from a surveillance system based on CCTV technology to a surveillance system based on POV technologies of vision. In the 2017 film The Circle by James Ponsoldt (Ponsoldt, 2017), the young and rampant worker Mae manages to witch-hunt a fugitive prisoner in ten minutes and twenty-one seconds by accessing in real time more than one billion POV mobile images world-wide, all connected to the Google-like social network The Circle. The so called SoulSearch technology proceeds to real time scanning the images produced by the community through a machine vision technology trained to recognize the fugitive's facial features.

The POV-opticon seems indeed to be characterized by the overlapping of features coming from both CCTV and POV regimes of visibility. The GIGA Selfie, a technological system patented in Australia which allows tourists to take images of themselves by controlling remotely with their phones a CCTV-like camera that is able to zoom from a CCTV frame to a POV selfie-like close-up of the users' faces, confirms this idea. The shrinking of the distance between CCTV and POV proceeds with the collection of data from users' phones and emphasizes the securitarian nature of the POV-CCTV circuit over the subjects and the space around them.

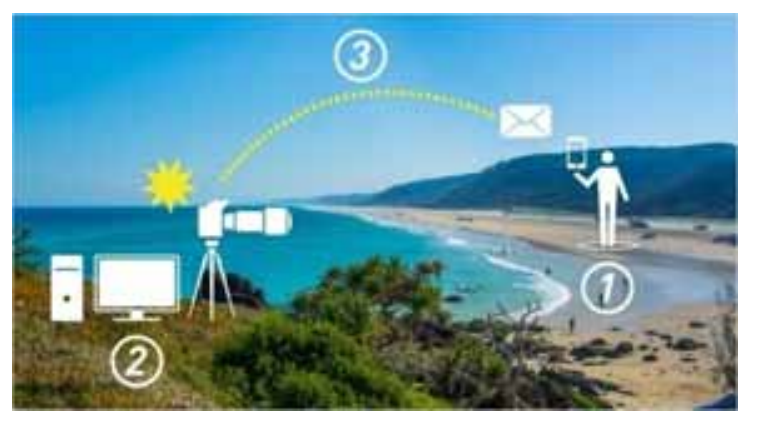

1. GIGA Selfie technology, Australia, 2015.

\footnotetext{
${ }^{3}$ I've approached the data double as data selfie when dealing in depth with the Algorithmic Facial Image (AFI).
} 
The shift from CCTV technologies to POV technologies as instrument of control is also evident in the case of the new Chinese social credit system, according to which citizens are tracked by a mobile phone app which datifies a stunning variety of actions (from buying alcohol to paying the bills in time) that serves to generate a citizen's data double and a consequent "social credit" aimed at controlling the overall citizen's agency (Rollet, 2018) - from being allowed or not to travel, to surfing online slower or faster than others, to having access or not to certain type of jobs. The Chinese social credit system works, once again, by overlapping the security quality of CCTV technologies with the real time access and proximity provided by POV technologies to their subjects.

POV-opticon replaces the modern Panopticon and function as the aesthetic format enabling one of the most aggressive surveillance assemblage ever seen in history. A form of surveillance which is not limited to tracking behaviors and analyzing data, but which actively aims at constructing the subjects by designing their (POV) data-doubles (Haggerty, Ericson, 200, pp. 605-622) and the custom-made (POV) post-truth reality tailored around them. In this sense, if the Panopticon is a regime of visibility functioning as an apparatus in charge of establishing a regime of truth within which certain games of truth can emerge (Foucault, 1975, p. 30) the POV-opticon - and the capability of algorithmic POV images to engineer reality (and truth itself) in ways that were before unimaginable, as we will see - produces the collapse of the regime of truth over the games of truth it underlines, giving rise to hermeneutic ambiguities defining the relation between the drive to visibility and the POV images that try to fulfill it.

\section{POV-opticon, Algorithmic Facial Image and post-truth}

The hermeneutic ambiguities defining the POVopticon seem related to the shrinking of the distance between body and interface typical of POV technologies and to the securitarian features these technologies inherited from CCTV technologies.

Furthermore, the alleged shrinking of the distance between 'fiction' and reality typical of the POVopticon is matched by the shrinking between an embodied 'singularity' (the subject) and a disembodied algorithmic agency. The most extreme forms of POV-opticon are being developed in relation to facial recognition systems, and the emergency of a new approach to the selfie aesthetic pushes even further the threshold of the Internet Post-truth condition. In this context, I've tried to define the Algorithmic Facial Image (AFI) as a new selfie aesthetic format especially characterized by the ambiguous games of truth it produces. AFI becomes popular with the viral diffusion over the internet of an open source deep neural networks capable of real time facial reenactment. The source spreads on the Reddit community to be used in the production of DeepFakes, a type of video image generated by the seamless overlapping of the face of famous Hollywood actresses over the body of pornographic ones while recording $X$-rated movies, with the face of the former assuming seamlessly the facial expression of the latter ${ }^{4}$ (Romano, 2018).

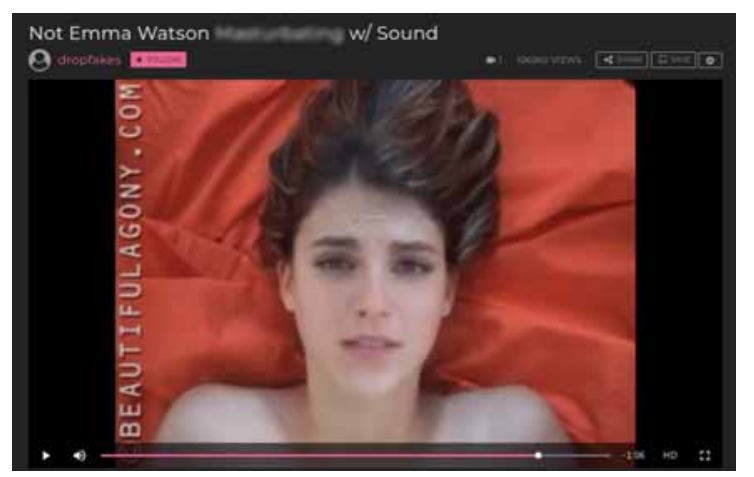

2. DeepFakes, Emma Watson, 2017.

In Arkangel, one of the episodes of the last Black Mirror series, a mother implants her daughter with a device which allows her to see in real time the images she is looking at from a POV perspective. Furthermore, the mother is provided with a user's friendly interface that gives her the possibility of deleting from the daughter's "sight stream" images she thinks could traumatize her kid. As a consequence of this technology, the kid grows incapable to recognize conflicts or violence and indeed incapable to behave accordingly when they appear in front of her eyes, after having been freed from the device.

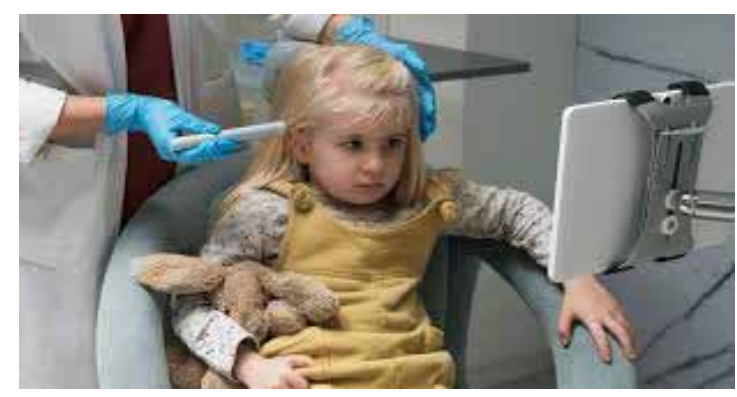

3. Arkangel, Black Mirror 4th season. 


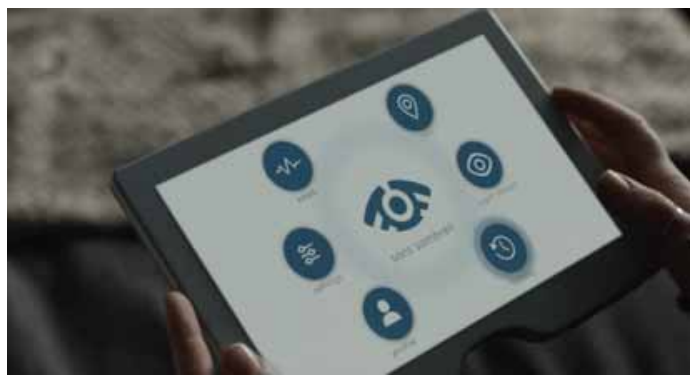

4. Arkangel technology user interface.

Arkangel technology is the most violent form of AFI ever imagined. The shrinking of the distance between body and technology annihilates, and the creation of memory is altered while being created at the same time via the constant visual commerce between the subject and the world recorded in firstperson and harnessed in real time by the technology. Arkangel simply substitutes reality with a revised version of it overlapping completely with reality itself. Post- truth becomes truth, and games of truth solidify into a POV micro-regime of truth which dictates the life of the kid and affect her way of relating with the world.

The POV-opticon shrinks the distance between body and interface and applies the securitarian features of CCTV technologies to POV technologies of vision turned into first-person tracking mechanisms. As a consequence, this process provokes the shrinking of the distance between fiction and reality, opening the space for the engineering quality of the algorithms to substituting one with the other. The games of truth turn into manufactured POV micro-regimes of truth which become post-truth because of the capability of images such as the AFI to replace reality with an algorithmically generated imagery. The POVopticon allows for the hyperproliferation of POV images and thus misleads the drive into feeling always closer to what Camel van Winkel calls the "missing visuals" (Winkel, 2005, p.1) - something like the engine of the drive itself - , and as a consequence novelty takes over truthfulness as the criteria for the drive to sustain itself. Meanwhile, the POV-opticon works on the assemblage of data extracted from POV technologies, and algorithms manufacture a reality which suits the drive as good as the reality itself, if not better - for the reason that this algorithmic reality is tailored on the drive to visibility of each subjects, and it contributes to the formation of the subject's POV data-double which in turn contributes to the formation of the algorithmic post-truth defining the POV-opticon.

\section{Drive to visibility and games of truth}

According to Camiel van Winkel, a Dutch art critic who not long ago published a book called "The regime of visibility", "there are too few images. The dynamics of contemporary culture are determined by visual shortage rather than visual surfeit. The demand for images - not just 'complex' or 'interesting' images, but any images - far outstrips supply. Life in a world dominated by visual media is subject to a permanent pressure to furnish the missing visuals; to visualize practices and processes that do not belong to the realm of the visual, or that aren't even visible as such. This is the regime of visibility" (Winkel, 2005, p.1).

Winkel proposes us to look at the drive to visibility rather than at the visible itself, and by doing so he invites us to think about the hyperproliferation of images as a way to control this impossible drive to bring everything into visibility, which Winkel tells us to be at the foundation of the regime of visibility itself. If we follow this idea, the ocean of images whatsoever we're drowning in is nothing more than the attempt to fulfill the impossible request and function as the instrument to sedate the drive and control it. Furthermore, if the drive to visibility is the force behind the regime of visibility, when the drive gets out of control, the care for accuracy and realism can get overshadowed.

In a study recently published by M.I.T. Initiative on the Digital Economy about "the spread of true and false news online" (Vasoughi, 2018), it seems that "falsehood diffused significantly farther, faster, deeper, and more broadly than the truth in all categories" (Vasoughi, 2018, p.1) and that "contrary to conventional wisdom, robots accelerated the spread of true and false news at the same rate, implying that humans, not robots, are more likely responsible for the dramatic spread of false news" (Vasoughi, 2018, p.1). How does this result speak to the drive to visibility Winkel is talking about? The indifference for the truthfulness of the information and the importance played instead by novelty - "false new was perceived as more novel then true news" (Vasoughi, 2018, p.1) seems to bridging over the gap between the drive to visibility and what it is visible, or brought to visibility. Novelty fulfills the drive to visibility better then truthfulness, and algorithms allows to harness novelty and reality at the same time, to the point of substituting one with the other. The shrinking of the distance between CCTV and POV regimes of visibility contributes to the shrinking between fiction and reality, and algorithmically driven POV regimes of visibility such as the one generated by the Algorithmic Facial Image (AFI) contributes in turn to the production of algorithmic novelty looking real.

The drive to visibility Winkel talks about is indeed defined by the games of truth emerging from the indifference of the drive towards the truthfulness of the information / image (as proved by the M.I.T. research), and from algorithmically driven POV regimes of visibility generated by the shrinking of 
the distance between POV and CCTV regime of visibility, and by the consequent shrinking between fiction and reality allowing the substitution of one with the other. The internal drive to visibility is captured by algorithms via the creation of seamlessly real imagery (such as in the case of the $\mathrm{AFI})$ that overcome the distinction between reality and fiction. Internet post-truth emerges because the drive to visibility and the algorithmic governance (Doneda, 2016) cross each other in the POV-opticon, where opaque and invisible algorithmic complexity co-exists together with the liveness and realness of POV images and provide the aesthetic and technological format for the hermeneutic ambiguities characterizing the games of truth of a POV-opticon form of visual governamentality.

\section{REFERENCES}

Azar, M. (2018) The algorithmic facial image and the relation between truth value and money Value. APRJA, A peer review journal about, Volume 7, Issue 1. Available from: https://www.academia.edu/37522968/The Algorithmic_Facial_Image_and the_Relati on_between_Truth_Value_and_Money_Val ue.

Clarke, R. (1988) Information Technology and Dataveillance. Commun. ACM 31,5. Available from: https://dl.acm.org/citation.cfm?id=42413.

Doneda, D. Almeida, V. (2016) What is algorithm governance? IEEE Internet computing.

Foucault, M. (1980-1981, [2014]) Subjectivité et vérité. Course au Collège de Fance. SeuilGallimard, Paris.

Foucault, M. (1975) Surveiller et punir. Naissance de la prison. Gallimard, Paris.
Haggerty, K. D., Ericson R. D. (2000) The surveillant assemblage. British Journal of Sociology Vol. No. 51 Issue No. 4. Available from: https://www.uio.no/studier/emner/matnat/ifi/ INF3700/v17/bakgrunnsnotat/the_surveilla nt_assemblage.pdf.

Lorenzini, D. (2017) La force du vrai. De Foucault à Austin. Le Bord de l'Eau, Lormont.

Lorenzini, D. (2015) What is a regime of Truth? Le Foucaldien 1/1. Open Access Journal for Research along Foucauldian Lines. Available from: https://foucaldien.net/articles/10.16995/lefo u.2/galley/2/download/.

Mirick D. \& Sanchez E. (1999) The Blair Witch project USA: Artisan Entertainment.

Montgomery, R. (1947) Lady in the Lake. Metro Goldwin-Mayer, USA.

Ponsoldt, J. (2017) The Circle. STXfilms, Europacorp, USA.

Rollet, C. (2018) The odd reality of life under China's all seeing credit score system. Wired. Available from: https://www.wired. co.uk/article/china-blacklist.

Vosoughi, S. Roy, D. Aral, S. (2018) The spread of true and false news online. M.I.T. Initiative on the Digital Economy Research Brief. Available from: http://ide.mit.edu/sites/ default/files/publications/2017\%20IDE\%20 Research\%20Brief\%20False\%20News.pdf.

Winkel, C. (2005) The regime of Visibility. Open! Platform for Art, Culture \& the Public Domain. Available from: https://www.online open.org/the-regime-of-visibility.

Winkel, C. (2016) The regime of Visibility. nai010 publishers, Rotterdam. 